\title{
INDISSOCIABILIDADE ENSINO, PESQUISA E EXTENSÃO POR MEIO DE UMA EXPOSIÇÃO MUSEOGRÁFICA SOBRE PRIMO LEVI
}

\section{THE INSEPARABILITY OF TEACHING, RESEARCH AND OUTREACH PROJECTS IN A MUSEOGRAPHIC EXHIBITION ABOUT PRIMO LEVI}

\author{
Luciana Massi* \\ ORCID: https://orcid.org/0000-0001-8761-3181 \\ Rafaela Valero da Silva** \\ ORCID: https://orcid.org/0000-0002-0613-6609 \\ Luciane Jatobá Palmieri*** \\ ORCID: https://orcid.org/0000-0003-0372-0911 \\ Carlos Sérgio Leonardo Júnior**** \\ ORCID: https://orcid.org/0000-0002-7316-0465
}

\section{Resumo}

Em 2019, comemoramos o Ano Internacional da Tabela Periódica e o centenário do nascimento de um notável químico e escritor judeu: Primo Levi. Isso nos levou a organizar ações de ensino, pesquisa e extensão que culminaram na exposição "Um quimiscritor no museu: ciência, literatura e direitos humanos com Primo Levi", do acervo permanente do Centro de Ciências de Araraquara da Universidade Estadual Paulista (UNESP). Este trabalho apresenta os processos de planejamento, montagem e mediação da exposição que integraram ensino, pesquisa e extensão, tendo como foco de divulgação científica a vida e a obra de Levi. Apresentamos alguns elementos sobre divulgação científica e a indissociabilidade ensino-pesquisa-extensão; trazemos aspectos sobre a rica e plural experiência de Levi; descrevemos as ações indissociadas de ensino, de pesquisa e, principalmente, de extensão; por fim, discutimos alguns resultados dessa ação integradora e extensionista. Concluímos que o hibridismo de Levi inspirou uma efetiva integração entre Ciência, Literatura e Direitos Humanos, bem como uniu e articulou atividades de ensino, pesquisa e extensão.

Palavras-chave: Química; Literatura; Direitos Humanos, Museu de Ciências.

Data recebimento: $15 / 09 / 2020$

Data de aceite: 03/03/2021

\begin{abstract}
The international year of the Periodic Table and the centenary of the notable chemist and Jewish writer Primo Levi was celebrated in 2019. This led us to organize teaching, research and outreach actions that culminated in the exhibition "A chemist / writer at the museum: science, literature and human rights with Primo Levi", a permanent collection of the Araraquara Science Center at São Paulo State University (UNESP, Portuguese acronym). This paper presents the processes of planning, assembly and mediation of the exhibition that integrated teaching, research and outreach activities, focusing on the dissemination of Primo Levi's life and work. The article presents some elements about scientific dissemination and the inseparability of teaching, research and outreach activities; aspects about Primo Levi's rich and plural experience; the inseparability of teaching, research and mainly, of outreach actions in addition to a discussion of some results of this integrative outreach action. It is concluded that Primo Levi's hybridism inspired an effective integration between Science, Literature and Human Rights as well as united and articulated teaching, research and outreach activities.
\end{abstract}

Keywords: Chemistry; Literature; Human Rights; Science Museum.

\footnotetext{
* Professora da Universidade Estadual Paulista "Júlio de Mesquita Filho" (UNESP), Araraquara - SP, Brasil. E-mail: luciana.massi@unesp.br ** Aluna de Mestrado da Universidade Estadual Paulista "Júlio de Mesquita Filho" (UNESP), Bauru - SP, Brasil. E-mail: rafaela.valero@unesp.br *** Aluna de Doutorado da Universidade Federal do Paraná (UFPR), Curitiba - PR, Brasil. E-mail: lujpal@gmail.com
} 
Embora presente na Constituição Federal desde 1988 (BRASIL, 1988) e no Fórum de Pró-Reitores de Extensão das Universidades Públicas Brasileiras (FORPROEX, 2006), a indissociabilidade ensino-pesquisa-extensão, que deveria caracterizar as universidades brasileiras, ainda enfrenta diversos obstáculos para sua efetivação. As exigências de produção de conhecimento inovador na pesquisa tendem a se chocar com os preceitos da transposição didática curricular, dificultando seu ensino direto nos cursos de graduação, e o investimento em pesquisas básicas ou aplicadas de ponta exige uma transposição tecnológica lenta e distante das demandas da comunidade em geral. Assim, a extensão, eventualmente, incorre nos riscos do assistencialismo, denunciados por Saviani (1991), perdendo seu potencial de retroalimentar a pesquisa e o ensino em uma Universidade efetivamente integrada com as demandas da sociedade.

Ao explicitar a "espiral da cultura científica" para mostrar o processo de produção e divulgação do conhecimento científico, situando a posição da divulgação científica, Vogt (2003), indiretamente, confirma a distância entre o público em geral e o especialista que a divulgação, assim como podemos supor também a extensão, vai tentar superar. O esforço em aproximar a Ciência das pessoas se mostra cada vez mais urgente em nossa sociedade e vem sendo enfrentado pela comunidade científica de diversas formas. Fruto de uma formação e salvação científica, Primo Levi também dedicou sua vida a essa tarefa, tendo escrito a obra intitulada $A$ Tabela Periódica, considerado o melhor livro popular de conteúdo científico de todos os tempos, segundo a Royal Institution of Great Britain. Para Levi (2016, p. 173), "Todos sabem o tipo de vida que leva um corsário, um aventureiro, um médico, uma prostituta. Sobre nós, químicos, transmutadores de matéria, ofício de ilustre ascendência, não há muitas pistas, e me parecia justo 'preencher uma lacuna"'.

Assim, inspirados pelos preceitos da indissociabilidade ensino-pesquisa-extensão, da divulgação científica e pela vida e obra de Primo Levi, produzimos uma exposição museográfica sobre este químico e escritor no Centro de Ciências de Araraquara (CCA) da Universidade Estadual Paulista "Júlio de Mesquita Filho" (UNESP). Neste artigo, descrevemos os processos envolvidos no planejamento, montagem e mediação da exposição que integraram ensino, pesquisa e extensão, tendo como foco central de divulgação científica a vida e a obra de Levi. Neste sentido, trazemos, primeiramente, alguns aspectos sobre a rica e plural experiência de Levi que motivou a exposição; em seguida, descrevemos as ações indissociadas de ensino, de pesquisa e, principalmente, de extensão, decorrentes desses fundamentos; por fim, discutimos alguns resultados dessa ação integradora e extensionista. 


\section{Química, Literatura e Direitos Humanos na vida e obra de Primo Levi}

Primo Levi (1919-1987) foi um químico judeu mantido como prisioneiro em Auschwitz durante o ano de 1944, cujos conhecimentos científicos foram determinantes para sua sobrevivência no campo de concentração. Sua formação humanística o fez escolher pela Química em um contexto em que as humanidades estavam contaminadas pela ideologia fascista na Itália, mas o suposto distanciamento da Química em relação à sociedade o decepcionou ao longo do curso. Levi esboçou alguns contos antes da experiência que marcou sua vida, porém, apenas após o fim da guerra, ele sentiu a necessidade de escrever como forma de testemunho e como tentativa de compreender aquela experiência humana que foi analisada em seu primeiro livro, É isto um homem?, publicado na Itália, em 1947. Durante o ano em que viveu em Auschwitz, Levi vivenciou um processo de desumanização que começou pela perda do seu próprio nome. Ao mesmo tempo, momentos esparsos e raros recuperaram sua humanidade: Levi se lembrou de um poema de Dante e ensinou italiano para outro prisioneiro por meio desse trecho; Levi foi selecionado, mediante uma prova de Química, para trabalhar em um laboratório dentro do campo de concentração. Relembrar desses conhecimentos e recordar a experiência das provas fez com que ele recuperasse parte da sua humanidade perdida.

Eu me formei em Turim em 1941, summa cum laude - e, ao dizer isso, tenho a clara sensação de que ele [o alemão que aplicava a prova] não vai acreditar. Realmente, nem eu estou acreditando. Basta olhar minhas mãos sujas e lanhadas, minhas calças de prisioneiro, incrustadas de barro. Sou eu, porém, eu, o bacharel de Turim, aliás, principalmente neste instante, não há dúvida quanto à minha identificação com ele, já que o reservatório das minhas lembranças de Química Orgânica, apesar de longa inatividade, inesperadamente atende dócil ao pedido. (LEVI, 1988, p. 157, grifo do autor).

Atuar como técnico em um laboratório o protegeu dos diversos riscos daquele ambiente; portanto, Levi valeu-se de conhecimentos técnicos aplicados a um projeto científico deplorável para sobreviver. Mais do que isso, sua perspectiva científica sobre a vida e a experiência humana permitiram que ele se distanciasse do horror ao qual era cotidianamente submetido, buscando compreendê-lo como um processo de desumanização. Após a publicação de $\dot{E}$ isto um homem?, Levi escreveu sobre a recuperação da sua humanidade (no livro $A$ trégua) e, adotando estilos de escrita diversos, seguiu discutindo literariamente sobre a relação entre Ciência e Sociedade, a profissão de químico e escritor, o trabalho, entre outros temas.

Segundo Maciera (2019, p. 89), “nenhuma página escrita pelo autor está dissociada de sua formação científica". Em $A$ Tabela Periódica, ele narra os acontecimentos de sua vida a partir de capítulos sobre elementos químicos. Coincidentemente, em 2019, celebramos o centenário do 
nascimento de Primo Levi e o Ano Internacional da Tabela Periódica. Segundo Maciera (2019, p. 121), essa obra é considerada um "modelo eficaz de divulgação científica", pois promoveu no grande público a divulgação de fundamentos da Química relacionando a narrativa aos elementos da Tabela Periódica. Em nossa percepção, tal proposta humanizou a Química.

O olhar do químico deixa marcas profundas na obra literária, que interessa, inclusive, aos intelectuais do mundo das ciências exatas, no qual tem grande repercussão alguns de seus livros, sendo admirado pela capacidade de expressar seu amor pela profissão e pela ciência, por fazer saltar aos olhos as dimensões de aproximação da ciência à realidade e à vida. (MACIERA, 2019, p. 110).

Assim, em toda sua obra é possível reconhecer a profunda integração entre Ciência e Literatura, sendo ambas voltadas para seu projeto social de igualdade entre os seres humanos. Após sobreviver a Auschwitz, Levi dedicou sua vida a denunciar a desumanização dessa experiência, buscando evitar sua repetição; para Maciera (2019, p. 98), ele condicionou "sua sobrevivência à necessidade de narrar sua experiência". Portanto, apostamos na potencialidade desse autor para apresentar a Química de uma forma mais rica e plural para a sociedade, ao mesmo tempo em que podemos abordar temas urgentes e atuais como os Direitos Humanos.

\section{Contexto e ações de ensino, pesquisa e extensão envolvidas na exposição}

Após ter contato com a vida e a obra de Primo Levi, percebemos a efeméride de seu centenário coincidir com o Ano Internacional da Tabela Periódica, em 2019, que é justamente o tema da Química que foi objeto de sua obra de divulgação científica mais importante, por meio da qual Levi parte de experiências pessoais e autobiográficas, transformando-as em Literatura por meio dos elementos químicos. Este fato nos levou a planejar a realização de uma exposição museográfica sobre Primo Levi, articulando projetos de pesquisa e ensino em nosso grupo que envolviam a vida e a obra do autor e o conhecimento químico em espaços não formais, que estão sintetizados na Figura 1 a seguir. 
Figura 1 - Esquema representativo da indissociabilidade ensino-pesquisa-extensão envolvendo a exposição museográfica "Um quimiscritor no museu".

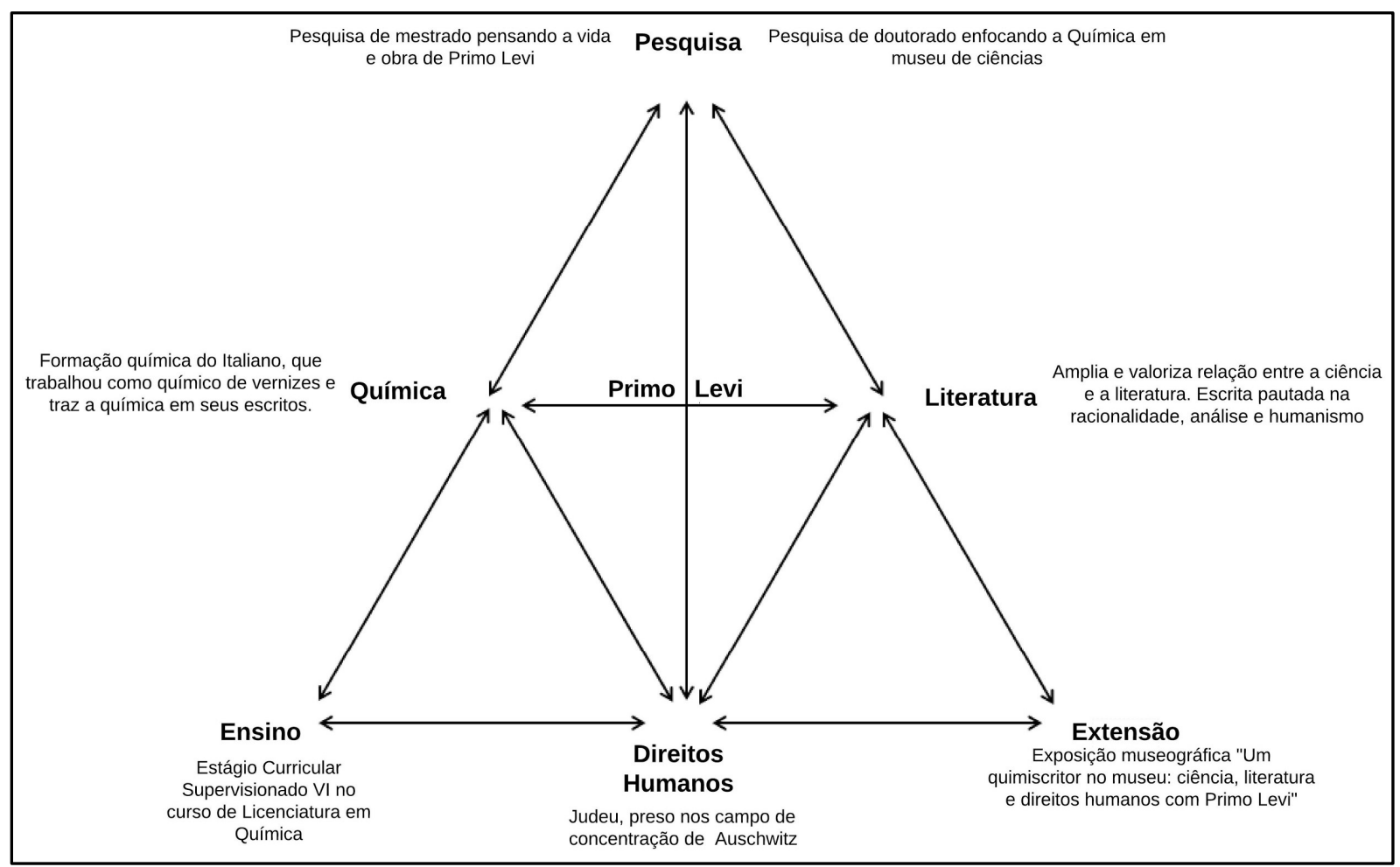

Fonte: Elaboração própria.

A presença da Química em espaços não formais é bastante tímida (PALMIERI; SILVA, 2017). Embora os museus de ciências representem há anos um dos espaços privilegiados de divulgação científica, capazes de atingir um público amplo, adotando uma linguagem atrativa e informativa, parece que essa Ciência encontrou pouco espaço para se desenvolver nesse modelo expositivo (STEOLA; KASSEBOEHMER, 2018). Tal dificuldade pode estar associada com uma visão distorcida de que a Química é apenas uma Ciência experimental (GIL PÉREZ et al., 2001). Partindo desse pressuposto, torna-se difícil incluir nos museus de ciências experimentos chamativos e perigosos, que demandam a condução por parte de um especialista, que exigem reagentes caros ou pouco acessíveis e que produzem resíduos de difícil descarte. Em pesquisa de pós-graduação, pretendíamos investigar a percepção equivocada da Química e explorar alternativas para inclúi-la em espaços expositivos não formais. Outra pesquisa de pós-graduação de nosso grupo investigava as relações entre Química e Literatura, presentes na vida e obra de Primo Levi, e nos forneceu um caminho fértil para explorar uma nova forma de exposição museográfica de conteúdos químicos. 
Diante dessas apostas iniciais, percebemos que seria muito importante incluir estudantes de graduação na experiência, assim como discutido por Campagnoli e Zanon (2019) sobre as potencialidades da formação de professores integrada à extensão. Embora existam algumas iniciativas isoladas, não é consenso na literatura nem está claramente indicado nos documentos oficiais, como em Brasil (2015), que os licenciandos devem vivenciar, como parte da sua formação, experiências de estágios em espaços não formais. No Instituto de Química (IQ) da UNESP de Araraquara, temos a vantagem de dispor de um Centro de Ciências, que já havia sido objeto de um dos estágios de formação do curso de licenciatura em Química (MASSI; LEONARDO JÚNIOR, 2016). Além disso, recebemos, em 2018, um pedido para oferecer o último estágio desse curso, de uma estrutura curricular anterior, que não havia sido cursado por apenas sete licenciandos, que tiveram diversas experiências (curriculares, extracurriculares e profissionais) no espaço escolar, ao longo da graduação. Entendendo que os espaços de educação não formal possuem particularidades e possibilitam contribuições para a cultura científica e para o trabalho pedagógico entre alunos e docentes (HARTMANN; SPERANDIO; OLIVEIRA, 2018), percebemos que seria uma ótima oportunidade para proporcionar a esses licenciandos uma vivência de estágio diferenciada e que culminasse na produção de uma exposição museográfica.

Uma das pesquisadoras em formação do grupo, que estudava a Química em museus em sua tese de doutorado, teve a oportunidade de atuar como docente dessa disciplina, por meio de um programa recém-criado em nossa instituição para qualificar os pós-graduandos e poder oferecer aos alunos seus conhecimentos sobre o tema, que foi seu objeto de estudo desde a graduação. Com a coordenação da professora responsável pela disciplina e orientadora principal do grupo de pesquisa, reformulamos o plano de ensino para que o estágio envolvesse a observação e produção de uma exposição museográfica sobre conteúdos químicos em museus de ciências. Essa disciplina é anual e foi oferecida aos sábados, não só por pedido dos alunos, mas também por ser coerente com uma proposta formativa, uma vez que os museus (ao contrário das escolas) se encontravam abertos naquele dia.

A proposta de ensino pautada nos espaços não formais e visando à produção de uma exposição foi apresentada aos sete licenciandos, que concordaram com a realização das atividades de ensino, pesquisa e extensão que estavam envolvidas e articuladas - segundo Parecer no 3.198.808 (14/03/2019) do Comitê de Ética em Pesquisa em Seres Humanos da Faculdade de Ciências - UNESP/Bauru. No primeiro semestre, foram realizadas visitas a quatro centros de ciências, nos quais os alunos produziram relatórios e análises sobre como a Química estava sendo exposta, visando construir um entendimento sobre qual Química eles pretendiam expor. Em seguida, os alunos tiveram contato com diversos contos, capítulos e excertos da obra de Primo Levi, com o intuito de se familiarizar com sua abordagem da Química e selecionar conteúdos e aspectos para compor a exposição.

Esse processo se deu entre o primeiro e o segundo semestre, sempre permeado por aulas teóricas e leitura e discussão de textos sobre os espaços não formais (SIMONNEAUX; JACOBI, 1997; CAZELLI et al., 1999; MARANDINO, 2001; RIBEIRO; FRUCCHI, 2007; MORI; 
CURVELO, 2016). No segundo semestre, demos início à transposição dos conteúdos selecionados sobre a vida e a obra de Primo Levi para imagens, textos, esquemas e experimentos que comporiam a exposição. O processo contou com a colaboração fundamental de uma estudante de mestrado, que estudava sobre o autor, e de um licenciando integrante do grupo de pesquisa que auxiliou na produção das artes da exposição. Em paralelo à disciplina, nos envolvemos na árdua tarefa de angariar fundos para custear a realização da exposição, concorremos em alguns editais sem sucesso, buscamos formas de financiamento coletivo, porém, conseguimos a maior parte do recurso da própria Universidade, bem como importantes doações de livros e mobiliário para a exposição.

O Centro de Ciências de Araraquara (CCA) da UNESP foi escolhido como espaço para receber a exposição e colaborou intensamente para sua realização, desde o planejamento da exposição e dos espaços expositivos até a sua montagem e divulgação. O CCA oferece um conjunto de atividades de divulgação científica, atendendo o público escolar e a comunidade em geral. $\mathrm{O}$ Centro foi criado na década de 1980 e há anos tem convênio com a Prefeitura de Araraquara, recebendo uma média de 3 mil crianças das escolas públicas e particulares da cidade e região por ano. Além disso, recebe o público espontâneo durante a semana e aos sábados. Neste espaço, existem diversas salas, organizadas a partir dos campos de conhecimento disciplinar (Biologia, Matemática, Física, Química, Mineralogia), além de algumas exposições temáticas, como a do Primo Levi, que inauguramos em outubro de 2019.

Os estudantes da licenciatura participaram ativamente do planejamento e da montagem da exposição, trazendo ideias originais, inspiradas na leitura de Levi, como a confecção de um uniforme híbrido de prisioneiro e químico e a construção de experimentos expositivos inspirados nos contos do autor, como ilustra a Figura 2.

Figura 2 - Imagens de produções dos licenciandos que compõem a exposição.
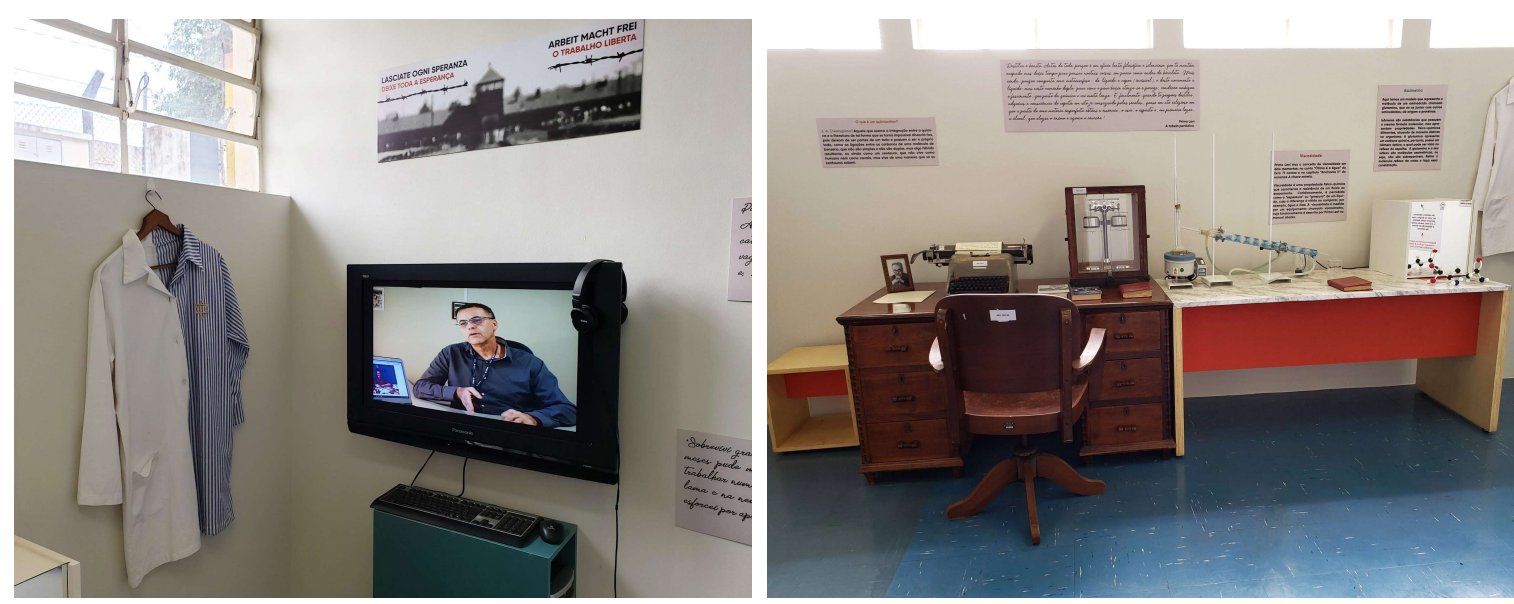

Fonte: Elaboração própria. 
A exposição ocupou parte de um prédio do Centro que abriga a biblioteca, a administração e algumas exposições temporárias, onde pudemos explorar uma grande entrada e uma sala para dispor o conteúdo da exposição, que foi dividida em seis seções, apresentadas na Figura 3: 1) a Tabela Periódica interativa, que mescla informações químicas, excertos de Primo Levi e amostras de substâncias acessadas aleatoriamente na forma de um jogo de caixasurpresa; 2) a cronologia da vida e da obra de Primo Levi, por meio de fotos e textos curtos; 3) seção de conteúdos químicos extraídos de sua obra e expostos por meio de animações e vídeos expostos no computador, e por meio de esquemas e imagens; 4) seção de Auschwitz com excertos e vídeos sobre a experiência traumática do escritor; 5) seção com uma mesa híbrida de escritor e químico de laboratório, com textos, máquina de escrever e experimentos; 6) seção de obras de literárias apresentando as produções do escritor por meio de vídeos e exposição dos livros de Primo Levi.

Figura 3 - Imagens das seções que compõem a exposição museográfica "Um quimiscritor no museu".

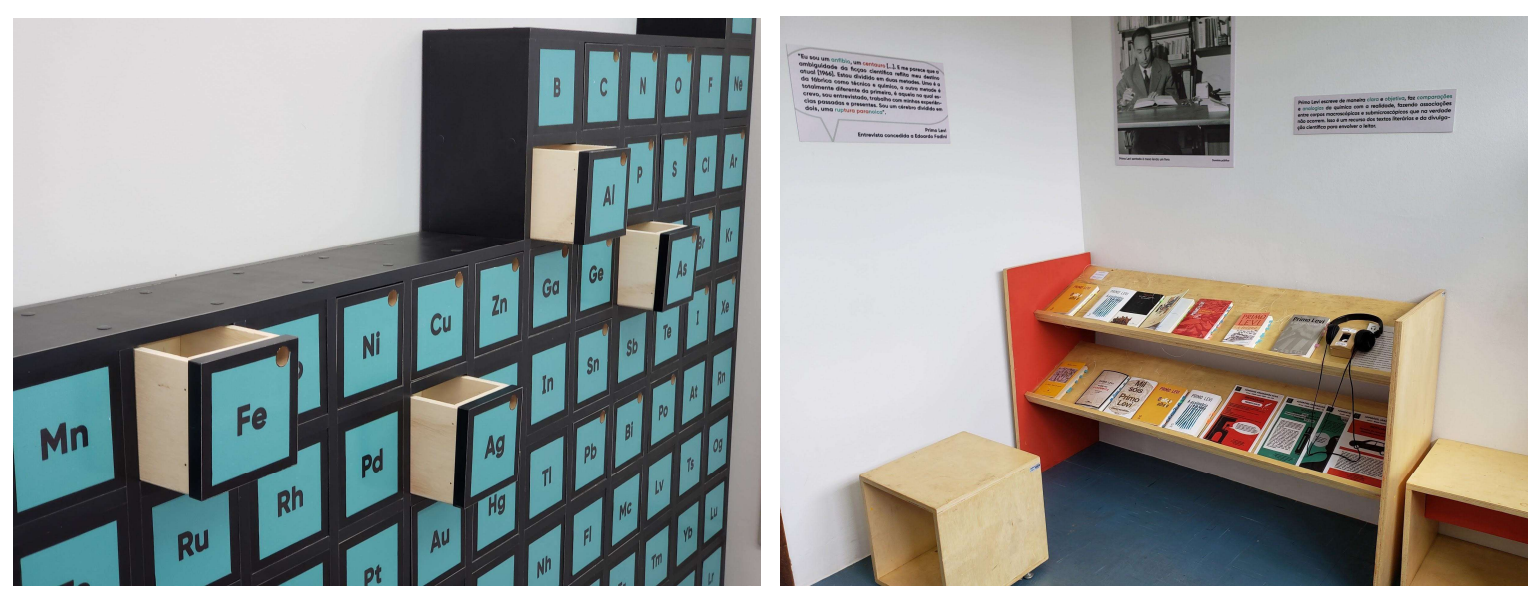

Fonte: Elaboração própria.

\section{Inauguração e efeitos da exposição nos envolvidos}

A exposição foi inaugurada em outubro de 2019, por meio de uma cerimônia que contou com uma palestra sobre Primo Levi e a presença de representantes da Universidade e coordenadores do CCA, bem como de todos os licenciandos envolvidos na exposição. $\mathrm{O}$ evento e o espaço foram divulgados na mídia local, sendo gravada uma entrevista com a coordenadora, que apresentou diversas imagens dos espaços expositivos e em outros meios de divulgação da cidade e da UNESP. Produzimos marcadores de livros sobre a exposição, que foram distribuídos na comunidade acadêmica e externa. Além da presença na inauguração, os licenciandos realizaram a mediação da exposição durante todo o mês de 
outubro, podendo interagir diretamente com o público escolar, e produziram um material de orientação para os outros mediadores.

Além da exposição no CCA, produzimos banners, que foram levados por alguns licenciandos para escolas públicas de nível médio, nos períodos diurno e noturno, visando ampliar a divulgação da exposição e dispor parte de seu conteúdo para o público que não teria acesso ao espaço físico. Esse material está apresentado na Figura 4. Além disso, diante da recente pandemia, parte do material da exposição foi disponibilizado em um website ${ }^{i}$, visando permitir as visitas virtuais, respeitando o distanciamento social.

Figura 4 - Banner resumindo e divulgando a exposição levado para escolas de nível médio de Araraquara.

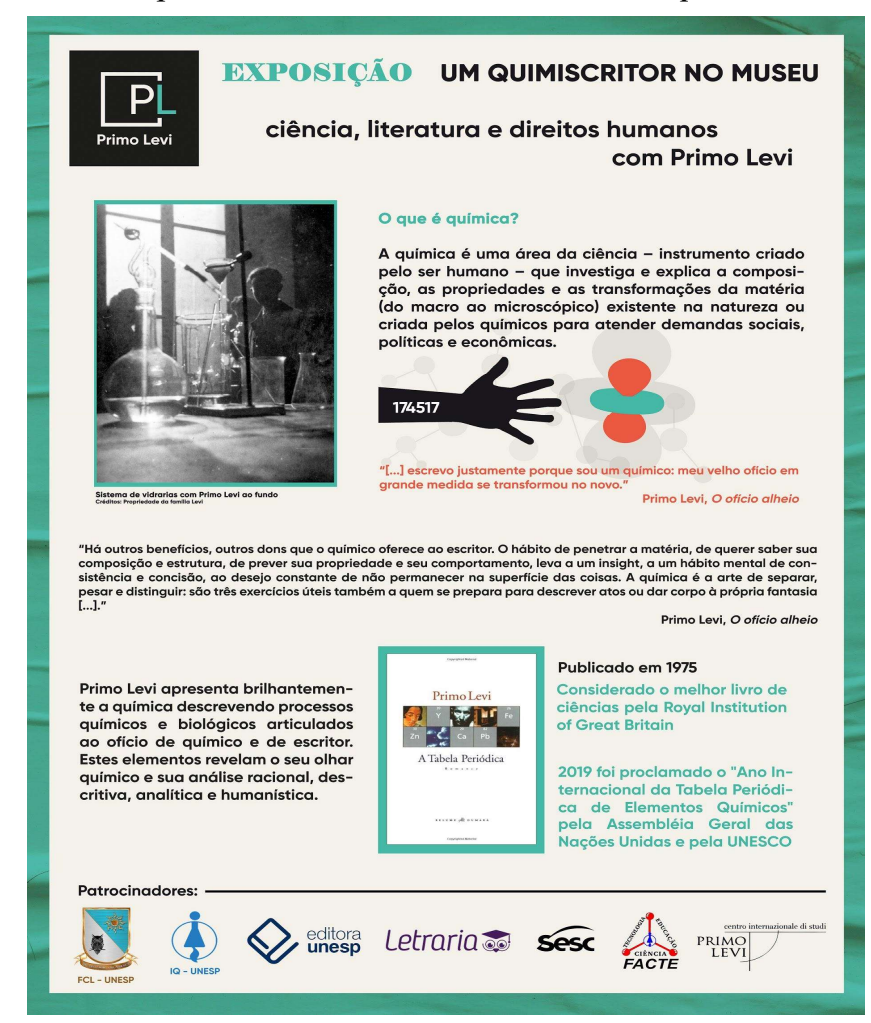

Fonte: Elaboração própria.

Acreditamos, assim, que promovemos uma efetiva integração entre as ações de ensino, pesquisa e extensão (BRASIL, 1988; FÓRUM, 2006), envolvendo estudos de pósgraduação, formação de estudantes da licenciatura e divulgação para um público amplo de uma nova visão de Ciência articulada com a Literatura. Apesar dos diversos desafios 
enfrentados para concretizar a exposição, todos os envolvidos ficaram muito orgulhosos com seu resultado, que teve um impacto muito positivo, tanto na comunidade acadêmica de cursos de Letras e Química, que não percebia essas possíveis articulações, quanto na comunidade externa, despertando o interesse de professores, estudantes e adultos em geral para os temas abordados por meio da vida e obra de Primo Levi.

O grupo de pesquisa pôde aprofundar seus estudos teóricos, retroalimentados pela vivência empírica com a realidade dos temas e o efeito que provoca em diversos públicos. Os estudantes de licenciatura tiveram contato com resultados de pesquisas participando tanto da construção dos dados quanto da contribuição na produção de conhecimento sobre os temas, além de ter contato com a divulgação científica e os espaços não formais. É amplamente discutido na literatura que os professores não têm como incluir os espaços não formais em seus projetos de ensino se não tiverem vivenciado essas experiências durante sua formação (MONTEIRO et al., 2016). Por meio dessa exposição, os alunos estudaram sobre espaços não formais, analisaram exposições já existentes e puderam planejar e mediar sua própria exposição. Além disso, o CCA, como espaço de extensão, pôde ampliar seu acervo e diversificar a abordagem do conteúdo químico para um público mais amplo, divulgando uma visão de Ciência mais humana e integrada.

\section{Agradecimentos}

Agradecemos ao CCA por ceder espaço e apoiar a montagem da exposição; à UNESP, pelo financiamento da exposição, em especial ao Departamento de Educação da Faculdade de Ciências e Letras e ao Conselho de Curso e à Fundação de Apoio à Ciência, Tecnologia e Educação (FACTE) do IQ; ao apoio, na forma de doações e divulgação da exposição por parte do Sesc de Araraquara, da Letraria E-ditora e da Editora UNESP; aos apoiadores provenientes da plataforma de financiamento coletivo Catarse; aos licenciandos do IQ por terem participado da produção, montagem e mediação da exposição; ao Fernando Estural, pela tradução de materiais audiovisuais; ao José Antonio Maruyama, pelo apoio e envolvimento com a montagem da exposição; e ao Centro Internazionale Di Studi Primo Levi por ceder imagens que foram utilizadas na exposição. 


\section{Referências}

BRASIL. Ministério da Educação. Resolução CNE/CP n 2, de 1 de julho de 2015. Diretrizes curriculares nacionais para a formação inicial em nível superior (cursos de licenciatura, cursos de formação pedagógica para graduados e cursos de segunda licenciatura) e para a formação continuada, 2015. Disponível em:

http://portal.mec.gov.br/docman/agosto-2017-pdf/70431-res-cne-cp-002-03072015-pdf/file. Acesso em: 22 abr. 2020.

BRASIL. Constituição (1988). Constituição da República Federativa do Brasil de 1998. Brasília, DF: Senado Federal, 1988. Disponível em: http://www.planalto.gov.br/ccivil_03/constituicao/constituicao.htm. Acesso em: 22 abr. 2020.

FORPROEX. Fórum de Pró-Reitores de Extensão das Universidades Públicas Brasileiras. Indissociabilidade ensino-pesquisa-extensão e a flexibilização curricular: uma visão da extensão. Porto Alegre: UFRGS; Brasília: MEC/SESu, 2006. Recuperado de https://www.ufmg.br/proex/renex/images/documentos/Indissociabilidade-eFlexibilizacao.pdf. Acesso em: 22 abr. 2020.

CAMPAGNOLI, K. R.; ZANON, D. P. Reflexões sobre as contribuições de um projeto de extensão para a formação inicial no curso de licenciatura em pedagogia. Conexão UEPG, v. 15, n. 2, p. 156-164, 2019.

CAZELLI, S.; QUEIROZ, G.; ALVES, F.; FALCÃO, D.; VALENTE, M. E.; GOUVÊA, G.; COLINVAUX, D. Tendências pedagógicas das exposições de um museu de ciência. In: ENCONTRO NACIONAL DE PESQUISA EM EDUCAÇÃO EM CIÊNCIAS, 2. Valinhos, 1999. [Anais...]. Valinhos, 1999. Disponível em: http://www.abrapecnet.org.br/enpec/ii-enpec/trabalhos/G48.pdf. Acesso em: 22 abr. 2020.

GIL PÉREZ, D.; MONTORO, I. F.; ALÍS, J. C.; CACHAPUZ, A.; PRAIA, J. Para uma imagem não deformada do trabalho científico. Ciência \& Educação, v. 7, n. 2, p. 125-153, 2001.

HARTMANN, A. M.; SPERANDIO, D. G.; OLIVEIRA, V. A. Divulgação e popularização da astronomia com o planetário móvel da UNIPAMPA. Conexão UEPG, v. 14, n. 3, p. 429-436, 2018.

LEVI, P. A assimetria e a vida: artigos e ensaios 1955-1987. São Paulo: Editora Unesp, 2016.

LEVI, P. É isto um homem? Tradução de Luigi Del Re. Rio de Janeiro: Rocco, 1988.

MACIERA, A. C. Primo Levi: a química entre literatura e ciência. Revista Cadernos de Letras, n. 34, p. 89-126, 2019. 
MARANDINO, M. Interfaces na Relação Museu-Escola. Caderno Brasileiro de Ensino de Física, v. 18, n. 1, p. 85-100, 2001.

MASSI, L.; LEONARDO JÚNIOR, C. S. Estágio supervisionado em espaço não formal: perspectivas e reflexões sobre uma experiência. In: LEÃO, A. M. C.; MUZZETI, L. R.; Luci Regina (orgs.). Perspectivas, práticas e reflexões educacionais. São Paulo: Cultura Acadêmica, 2016. p. 215-239.

MONTEIRO, B. A. P.; MARTINS, I.; JANERINE, A. S.; CARVALHO, F. C. The issue of the arrangement of new environments for science education through collaborative actions between schools, museums and science centres in the Brazilian context of teacher training. Cultural Studies of Science Education, v. 11, p. 419-437, 2016.

MORI, R. C. M.; CURVELO, A. A. S. O pensamento de Dermeval Saviani e a educação em museus de ciências. Educação e Pesquisa, v. 42, n. 2, p. 491-506, 2016.

PALMIERI, L. J.; SILVA, C. S. Museus de Ciências e o Ensino de Química: análise sobre a produção acadêmica em periódicos e eventos. Debates em Ensino de Química, v. 3, n. 2, p. 70-92, 2017.

RIBEIRO, M.G.; FRUCCHI,G. Mediação - a linguagem humana dos museus. In: MASSARANI, L. (org.) Diálogos \& Ciência: mediação em museus e centros de ciência, p. 68-74, 2007. Disponível em: http://www.fiocruz.br/omcc/media/EVCV_KOPTCKE_Analisando_a_dinamica.pdf. Acesso em: 22 abr. 2020.

SAVIANI, D. Ensino público e algumas falas sobre universidade. 5. ed. São Paulo: Cortez/Autores Associados, 1991.

SIMONNEAUX, L.; JACOBI, D. Language constraints in producing prefiguration posters for Scientific exhibition. Public Understanding of Science, v. 6, p. 383-408, 1997.

STEOLA, A. C. DA S.; KASSEBOEHMER, A. C. O espaço da química nos centros e museus de ciências brasileiros. Química Nova, v. 41, n. 9, p. 1072-1082, 2018.

VOGT, C. A espiral da cultura científica. ComCiência, Campinas, jul. 2003. Disponível em: http://www.comciencia.br/reportagens/cultura/cultura01.shtml. Acesso em: 22 abr. 2020.

\footnotetext{
'A exposição virtual pode ser visitada acessando o link: https://sites.google.com/unesp.br/quimiscritor
} 